Vol.1 No.3, Autumn 2020

\title{
Improving Therapeutic Communication Skills Based on the COMFORT Communication Curriculum
}

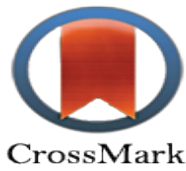

CrossMark
click for updates

Ghiyasvandian $\mathrm{Sh}^{1}$, Mardanian Dehkordi L 2*

1- Department of Medical Surgical Nursing, School of Nursing and Midwifery, Tehran University of Medical Sciences, Tehran, Iran.

2- Department of Adult Health Nursing, School of Nursing and Midwifery, Isfahan University of Medical Sciences, Isfahan, Iran.

Corresponding Author: Mardanian Dehkordi L, Department of Adult Health Nursing, School of Nursing and Midwifery, Isfahan University of Medical Sciences, Isfahan, Iran.

Email: mardanian@nm.mui.ac.ir

Received: 9 November 2019

Accepted: 10 December 2019

\begin{abstract}
Introduction: Communication is an essential part of ethical behaviors and a vital element of all nursing activity, including prevention, treatment, rehabilitation, education and health promotion so in this article communication strategies provided based on the COMFORT Communication curriculum (Comfort Communication Project, Los Angeles, CA).

Method: In this study, margin, PubMed and google scholar databases were searched with the keywords nursing, therapeutic communication and cancer and related studies were analyzed.

Results: findings shows that COMFORT Communication Project provides appropriate strategies for therapeutic communication between nurses and patients. This project point to the seven strategy for improving communication that are Communication, Orientation, Mindful communication, Family, Openings, Relating, and Team.

Conclusion: Using the Comfort Communication project and its suggested strategies will improve the nurse's communication skills. Therefore, it is suggested that these strategies be considered into nursing students' curriculum and continuing education programs for nurses.
\end{abstract}

Keywords: Communication; Oncology nursing; Nursing education.

\begin{tabular}{|l|l|}
\hline \multicolumn{3}{|c|}{ Access this article online } \\
\hline
\end{tabular}




\title{
COMFORT بهبود مهارتهاى ارتباط درمانى بر اساس برنامه ارتباط
}

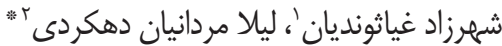

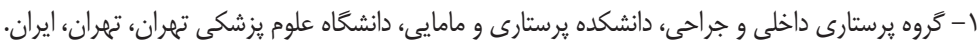

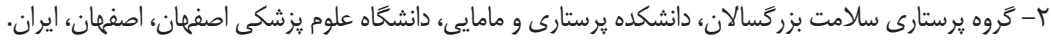

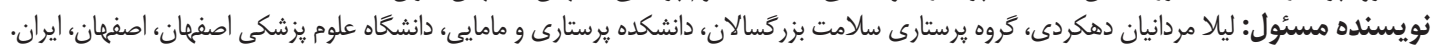

ايميل mardanian@nm.mui.ac.ir

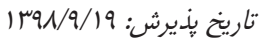

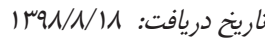

مقدمه: ارتباط بخش مهمى از رفتارهاى اخلاقى و عنصرى حياتى در تمام فعاليت هاى يرستارى، از جمله يِيشگيرى، درمان، توانبشى،

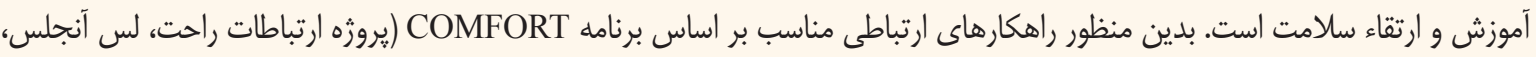
كاليفرنيا) ارائه مى كردد.

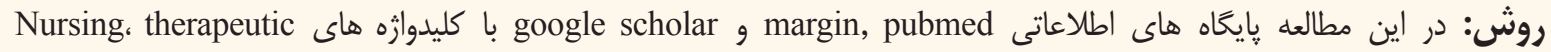
cancer و communication

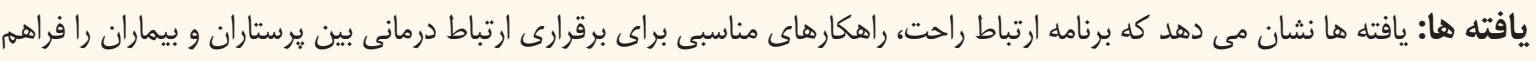

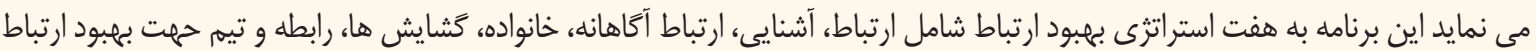
اشاره مى كند.

نتيجه كَيرى: استفاده از مدل ارتباطى COMFORT استفاده از استراتزيهاى ييشنهاد شده در آن به بهبود ميهارتهاى ارتباطى يرستاران

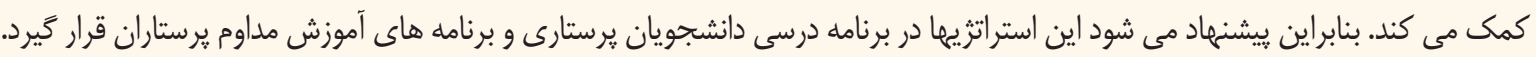

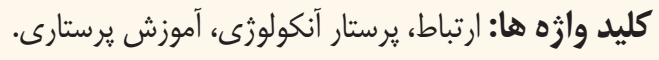

بودن زبان (+1) و نبود حمايت هاى سازمانى مورد غفلت قرار گرفته و به ارتباطات يك طرفه و مراقبتهاى روتين يرستارى منجر مى مَرد مقلdمه (T)، (1) و در برخى موارد به ابراز شكايات و بكاركيرى نادرست دستورات توسط بيماران مى انجامد (ع).).

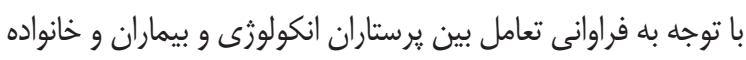

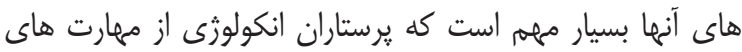

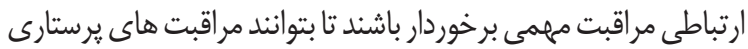
از افراد مبتلا به سرطان را با كيفيتى مناسب ارائه دهند (سا) إ). شواهد

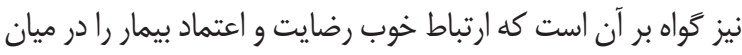
يرستاران، بيماران و اعضاى خانواده افزايش داده وييامدهاى درمان را ران

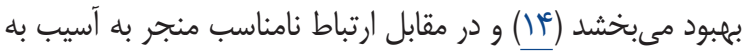

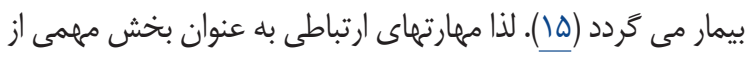
آموزش يرستارى به شمار مى آيد، هرا كه يرستار حرفه اى براى بيان خود و درك متقابل افراد نياز به مهارتهاى ارتباط مناسب دارد (+1). اما على رغم اين موضوع و با وجود زمان زيادى كه برستار با بيمار ارتباط بخش مهمى از رفتارهاى اخلاقى (l) و عنصرى حياتى در

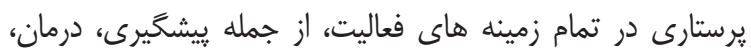

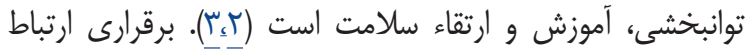

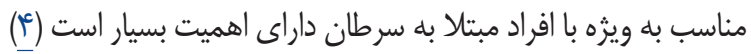
و در اين بين يرستاران داراى نقشى متفاوت از يزشك و ساير اعضا

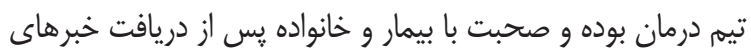
بد، كفتخو در مورد نكرانىهاى معنوى و دينى و صحبت با ساير اعضا تيم درمان و انكولوزى در مورد بيمار و خانواده وى، به عهيده آنانيان است كه كاه در سايه نداشتن مهارتهاى همدلى، ارتباط ضعيف بين حرفه اى و كمبود مهارت در مورد نحوه شروع بحث در مورد بايان

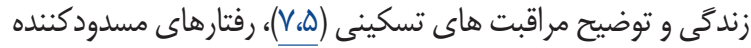

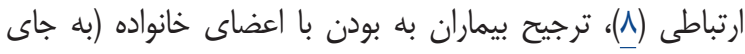

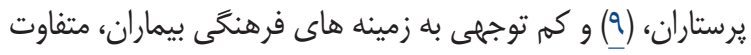


آشنايى يرستاران انكولوزى يلى بين زبان يزشكى و زبان زندكى روزمره ايجاد

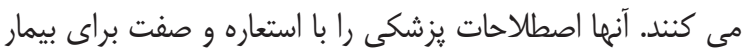
معنا مى كنند و آنجه را كه بيمار و خانواده درك كرده اند را به تيه إنيه

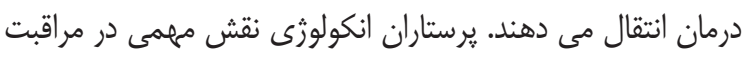

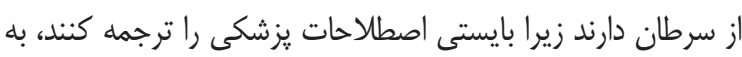

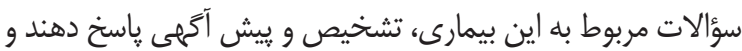

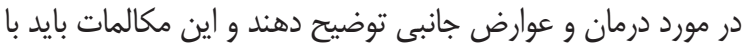
سواد سلامتى خانواده بيمار مطابقت داشته باشد (1) (1).

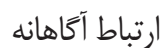

ارتباطات آكاهانه در مراقبت تسكينى شامل كاهش كفتكو با خود به

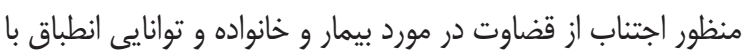

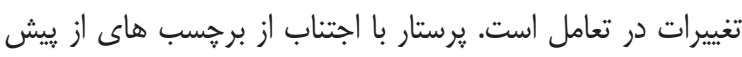
تعيين شده و خودآكاهى و كنترل استرسهاى ارتباطى ارتباط آكاهانه

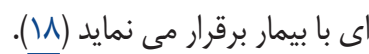
خانواده مشاهده الكَوهاى برقرارى ارتباط در خانواده و مراقبان خانوادكى و

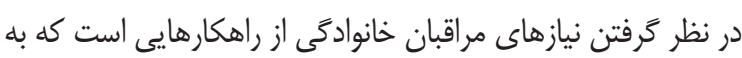

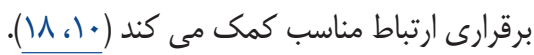
كشايش براى برقرارى روزنه هايى براى ارتباط مناسب شناسايى زمينه هاى مشترك با بيماران بسيار كمى كننده است (•(1) 11). رابطه ها ارتباط با بيمار / خانواده مستلزم ايجاد اعتماد و ايجاد رابطه است.

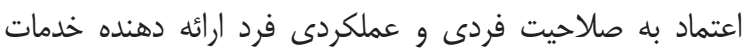
درمانى بستخى دارد و از طريق حمايت عاطفى درك شده بيمار، توانايى به اشتراك كذاشتن احساسات شخصى و همكارى با خانواده

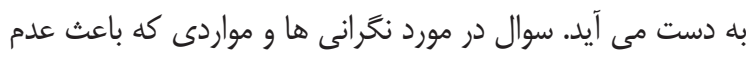
اطمينان بيمار مى كر دد به برقرارى اين رابطه كمى مى كند. بايد در نظر داشت كه بايستى به تمامى اهداف بيمار و خانواده بايد در اين رابطه توجه داشت (•l، (1). تيمم توسعه همكاريهاى بين حرفه ایى و تمايز تشكيل كروه از كارتيمى

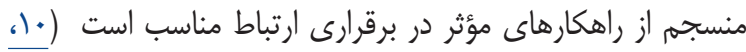

\section{بحث و نتيجه كيرى} يافته هاى فوق نشان مى دهد كه استفاده از راهكارهاى ارائه شده در
مى كذراند، آموزش مهارتهاى ارتباطى به طور سنتى براى ساير حرفه

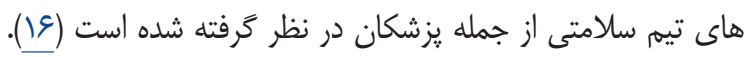

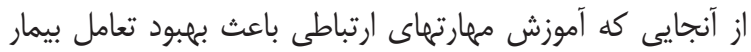

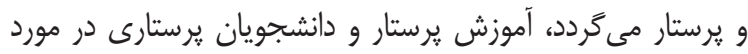
ارتباط يرستار - بيمار امرى ضرورى است (IV) ارتباط درمانى مبتنى بر هدف و به منظور رفع نيازهاى بيمار طرح ريزى شده و بايستى در محدوده مرزهاى حرفه ایى يعنى محدوده بين آسيب يذيرى بيمار و قدرت حرفه اى برستار برقرار شود (+1).

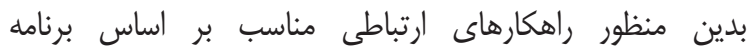
COMFORT (يروزه ارتباطات راحت، لس آنجلس، كاليفرنيا) ارائه

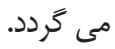
Pub Med, روش كار: براى انجام اين مطالعه پِيخاه هاى اطلاعاتى therapeutic با كليد وازهه هاى Iran doc google scholar communication T nursing cancer و مطالعات مرتبط به زبان انخًليسى يا فارسى انتخاب و مورد تحليل

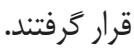

\section{يافته ها} مرور مطالعات انجام شده نشان مى دهد كه برنامه ارتباط راحتراهكارهاى مناسبى براى برقرارى ارتباط درمانى بين يرستاران و بيماران را فراهم مى نمايد. كلمه COMFORT مخفف هفت برائ وازه ارتباط، آشنايى، ارتباط آًَاهانه، خانواده، كشايش ها، رابطه و تيم

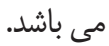
ارتباط اساسى براى ارائه مراقبت جامع و بهبود كيفيت زندگى بيماران، يرستار بايد روايت بالينى را در ارتباط با بيمار و خانواده در نظر داشته

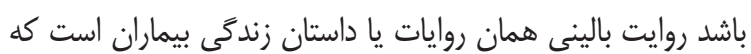

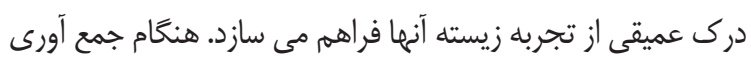
اطلاعات در مورد بيمار / خانواده ، يرستاران بايد از بيمار/ خانواده بخواهند كه داستان سرطان را به خاطر بياورد. داستان يردازى دي نوعى طبيعى از تعامل انسان است و داستانهاى بيمارى نشان

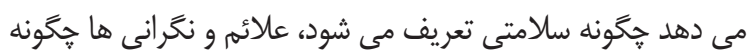

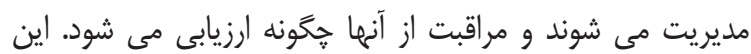
داستانها بينشى براى يرستاران فراهم مى سازد كه از طريق ارزيابى إنى

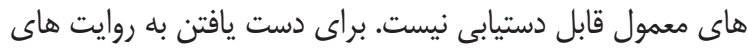

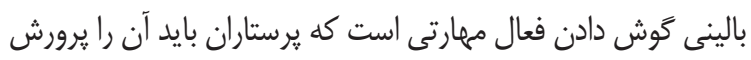

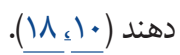


بخش كمك مى كند. درمرحله خاتمه و زمان بايان گرفتن ارتباط درمانى بيمار و يرستار اگر نيازهاى بيمار برطرف شده باشد احساس خوشايندى در يى خواهد داشت و در صورتى كه بيمار همجنان به حمايت نياز داشته باشد ممكن است منجر به اضطراب بيمار كردد

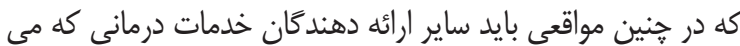
توانند به وى كمك كنند، معرفى شوند (•) از آنجايى كه آموزش مهارتهاى ارتباطى باعث بهبود تعامل بيمار

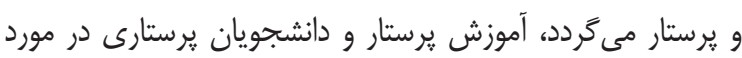
ارتباط برستار - بيمار امرى ضرورى است. استفاده از مدل ارتباطى بردي Comfort

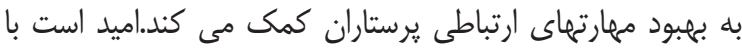
بكاركيرى اصول ياد شده، اين مهم به شيوه صحيح انجام و نيازهاى برى بيماران در يرتو ارتباط مناسب پاسخ داده شوند.

\section{References}

1. Purtilo RB, Haddad AM, Doherty RF. Health professional and patient interaction. 8 th ed. St. Louis: Elsevier; 2014.

2. Kourkouta L, Papathanasiou I. Communication in nursing practice. Mater Sociomed. 2014; 26 (1): $65-67$.

3. Abdolrahimi M, Ghiyasvandian S, Zakerimoghadam M, Ebadi A. Therapeutic communication in nursing students: A Walker \& Avant concept analysis. Electronic physician. 2018 Aug; 9 (8): 4968.

4. Nasiripour A, Saeedzadeh ZS, Sabahi Beedgoli M. [Correlation between nurses communication skills and inpatient service quality in the hospitals of Kashan University of Medical Sciences]. JHPM. 2012; 1(1): 4554.

5. Zakerimoghadam M, Ghiyasvandian S, Leili AK. Nurse-physician collaboration: The attitudes of baccalaureate nursing students at Tehran University of Medical Sciences. Iranian Red Crescent Medical Journal. 2015 Apr; 18 (4).

6. Chen $\mathrm{CH}$, Raingruber B. Educational needs of inpatient oncology nurses in providing psychosocial care. Clin J Oncol Nurs 2014;18:15. 12).

7. Banerjee SC, Manna R, Coyle N, et al. Oncology nurses' communication challenges with patients and families: a qualitative study. Nurse Educ Pract 2016; 16: 183 - 201.
برنامه comfort باعث بهبود مهارتهاى ارتباطى يرستاران مى گردد. با اين وجود يكى از نكات بسيار مهمى كه در كنار راهكارهاى اشاره بعار بهار شده بايد بدان توجه داشت اين است كه هدف و مدت زمان ارتباط از ابتداى برقرراى ارتباط و در مرحله معارفه توسط يرستار مشخص مى تى شود اهداف بايد با مشار كت بيمار و بر اساس نيازهاى وى تعيين كردد.

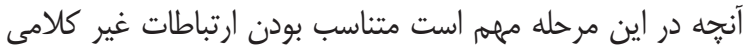
با ارتباط كلامى، تماس جشمى و عدم استفاده از حالتهاى تدافعى مانند قفل كردن بازوها در هم است. شروع مناسب ارتباط منجر به اعتماد دو طرفه و تعيين نيازهاى درمانى بيمار مى گردد. مرحله اجرا و زمان برقرارى ارتباط درمانى با بيمار نيز در كنار تكنيك هاى مانند خوددارى از بيش قضاوت كردن، عدم استفاده از برجسبها، سكوت هنكام صحبت كردن بيمار وكوش دادن فعال؛ در نظر كيرى فرد برد به عنوان انسانى منحصر به فرد، استفاده از مترجم هنگام متفاوت بودن زبان بيمار و يرستار، همدلى و تاييد بيمار نيز به موفقيت اين

8. Schofield NG, Green C, Creed F. Communication skills of health-care professionals working in oncology-can they be improved? European Journal of Oncology Nursing. 2008 Feb 1; 12 (1): 4 - 13.

9. Kvåle K. Do cancer patients always want to talk about difficult emotions? A qualitative study of cancer inpatients communication needs. European Journal of Oncology Nursing. 2007 Sep 1; 11(4): 320 - 7.

10. Black, Beth. Professional Nursing-E-Book: Concepts \& Challenges. Elsevier Health Sciences, 2013.

11. Tay LH, Ang E, Hegney D. Nurses' perceptions of the barriers in effective communication with inpatient cancer adults in Singapore. Journal of clinical nursing. 2012 Sep; 21 (18-18): 2647-58.

12. Dithole, K. S., Thupayagale-Tshweneagae, G., Akpor, O. A., \& Moleki, M. M. (2018). Communication skills intervention: promoting effective communication between nurses and mechanically ventilated patients. BMC Nursing, 16, 74. http://doi.org/10.1186/s12912-018-02685 .

13. Baer L, Weinstein E. Improving oncology nurses' communication skills for difficult conversations. Clin J Oncol Nurs 2013;18:45-51.

14. Rassouli M, Zamanzadeh V, Abbaszadeh A, Nikanafar A, Alavi-Majd H, Mirza Ahmadi F et al .PATIENT-CENTERED COMMUNICATION 
BARRIERS: EXPERIENCES OF PATIENTS WITH CANCER, THEIR FAMILY MEMBERS AND NURSES. J Urmia Nurs Midwifery Fac. 2014; 11 (10) URL: http://unmf.umsu.ac.ir/ article-1-1640-en.html.

15. Leonard M, Graham S, Bonacum D. The human factor, the critical importance of effective teamwork and communication in providing safe care. Quality \& Safety in Health Care. 2005;13:85-90. http://dx.doi.org/10.1136/ qshc.2004.010033.

16. Boyle DA, Anderson WG. Enhancing the communication skills of critical care nurses:focus on prognosis and goals of care discussions. Clin Commun. 2015; 54: 35 - 46.

17. Happ MB, Garrett KL, Tate JA, et al. Effect of a multi-level intervention on nurse-patient communication in the intensive care unit: results of the SPEACS trial. Heart Lung. 2014; 43: 8998.

18. Wittenberg E, Reb A, Kanter E. Communicating with Patients and Families Around Difficult Topics in Cancer Care Using the COMFORT Communication Curriculum. InSeminars in oncology nursing 2018 Aug 1 (Vol. 34, No. 3, pp. 264 - 273). WB Saunders. 